\title{
Plasma electrolytic oxidation coatings on Mg-alloys for improved wear and corrosion resistance
}

\author{
R. O. Hussein ${ }^{1}$, X. $\mathrm{Nie}^{2}$ \& D. O. Northwood ${ }^{2}$ \\ ${ }^{1}$ Higher Colleges of Technology, Al Ain, United Arab Emirates \\ ${ }^{2}$ University of Windsor, Canada
}

\begin{abstract}
Due to their high chemical reactivity, relatively low melting point and low hardness, magnesium and magnesium alloys have relatively poor corrosion and wear resistance. Since both corrosion and wear are surface phenomena, a number of surface engineering techniques have been used to improve corrosion and wear performance. Whilst some surface hardening/strengthening methods have led to improvements in wear properties, they have not, in themselves, significantly improved the corrosion performance. Plasma electrolytic oxidation (PEO) has the potential to produce hard, compact oxide coatings that are well adhered to the magnesium alloy substrate. Such coatings can provide both improved wear and corrosion resistance. In this contribution, it is shown how the nature of the PEO oxide coatings (thickness, microstructure, porosity, phase content, composition) can be changed by changing the PEO processing parameters (substrate alloy, electrolyte, current or voltage, processing time); this, in turn, effects the corrosion and wear performance. All PEO-coatings have a three-layer structure with a porous outer layer, an intermediate dense layer and a thin inner dense layer. From a corrosion aspect, the performance of coatings is determined by the time taken for corrosion to initiate since this is much shorter than the time taken for the coating to degrade. For PEO-coated Mg-alloys, this initiation time is primarily determined by the thickness, porosity and phase content of the inner dense layer at the coating/substrate interface. With respect to tribological properties, the coefficient of friction (COF) in dry sliding wear increases with increasing surface roughness of the PEO coatings. The wear rate is primarily determined by the thickness and hardness of the intermediate dense layer. Coatings containing less
\end{abstract}


porosity and higher spinel-phase $\left(\mathrm{MgAl}_{2} \mathrm{O}_{4}, \mathrm{Mg}_{2} \mathrm{SiO}_{4}\right)$ content are harder and more wear-resistant.

Keywords: magnesium alloys, PEO coatings, three-layer structure, corrosion, tribological properties.

\section{Introduction}

Magnesium is the lightest structural metal. In addition to its low density, a high specific strength, specific stiffness, good castability and weldability, good damping and good electro-magnetic shielding make magnesium alloys a desirable material for many applications [1]. However, their lower formability, relatively low creep resistance at elevated temperature and high chemical reactivity with associated low corrosion and wear resistance, limits the use of magnesium alloys in many industries [2].

It is generally recognized that magnesium has poor wear resistance and that this is related to a low hardness [3]. The main mechanism for improving the mechanical properties is precipitation hardening, e.g. by adding aluminium which forms a $\mathrm{Mg}_{17} \mathrm{Al}_{12}$ intermetallic phase which increases tensile strength and hardness. However almost all elements used so far for alloying increase magnesium's susceptibility to corrosion. The relatively poor wear performance of magnesium and its alloys is also related to magnesium's high reactivity and relatively low melting point. Surface treatment to form coatings which produce a protective ceramic, polymer or composite layers is considered as one of the most effective ways for corrosion and wear protection. Such coatings should be uniform, pore free, relatively thick, hard, well adhered, flexible to withstand an overload and insulating to minimize corrosion. Plasma electrolytic oxidation (PEO) fulfils most of these requirements and has been used for depositing a well adhered ceramic coating on light-weight metals $(\mathrm{Mg}, \mathrm{Al}, \mathrm{Ti}, \mathrm{Zr})$ that provides not only corrosion protection but also enhanced wear properties, hardness and toughness with better thermal stability and dielectric properties [4-7].

PEO is a process that transforms the magnesium metal surface into thick, ultrahard ceramic oxides by a plasma discharge in an electrolytic bath $[8,9]$. The PEO process for light-weight metals is strongly influenced by such parameters as electrolyte composition and concentration, current or voltage applied and substrate alloy [10]. Generally, these parameters have a direct influence on the phase transformations, crystallization and sintering.

Due to the existence of temperature gradients between the inner and outer layer of the coating, PEO coatings on light alloys have been found to have a three-layered structure [8]. The porous outer layer usually has poor mechanical properties. The intermediate layer is relatively dense and can provide good corrosion protection. The third (barrier) layer is a very thin interface layer (few hundred $\mathrm{nm}$ to $1 \mu \mathrm{m}$ in thickness) is well adhered to the substrate and ultimately provides the best corrosion performance [8]. Mg alloy parts used for automotive and aerospace applications including helicopter gearbox covers, pistons and cylinders, are subject not only to corrosion but also to mechanical wear. 
The electrochemical formation of surface oxide layers can occur through different mechanisms depending on the electrolyte, e.g. silicates, aluminates, phosphates. The PEO coatings are usually produced by AC or bipolar current mode, containing both anodic and cathodic components. An oxide layer formation is induced both by the ionic component of the current which is transmitted via surface discharges and by the anodizing current passing across the surface which is free of discharges [4]. The other components of the current cause secondary electrochemical processes which lead to liberation of electrode gases $\left(\mathrm{H}_{2}\right.$ and $\left.\mathrm{O}_{2}\right)$ and anodic dissolution of the lightweight metal, where for magnesium alloys the main electrochemical reactions occurring at the metal/oxide and oxide/electrolyte interfaces are as follows [11]:

Metal-oxide interface:

$$
\begin{gathered}
\mathrm{Mg} \rightarrow \mathrm{Mg}^{2+}+2 \mathrm{e}^{-} \\
4 \mathrm{OH}^{-} \rightarrow 2 \mathrm{H}_{2} \mathrm{O}+\mathrm{O}_{2} \uparrow+4 \mathrm{e}^{-}
\end{gathered}
$$

Oxide-electrolyte interface:

$$
\begin{gathered}
\mathrm{Mg}^{2+}+2 \mathrm{OH}^{-} \rightarrow \mathrm{Mg}(\mathrm{OH})_{2} \\
\mathrm{Mg}(\mathrm{OH})_{2} \rightarrow \mathrm{MgO} \downarrow+\mathrm{H}_{2} \mathrm{O} \\
\mathrm{Mg}^{2+}+2 \mathrm{AlO}_{2}^{-} \rightarrow \mathrm{MgAl}_{2} \mathrm{O}_{4} \downarrow \\
2 \mathrm{Mg}^{2+}+\mathrm{SiO}_{3}^{2-}+2 \mathrm{OH}^{-} \rightarrow \mathrm{Mg}_{2} \mathrm{SiO}_{4} \downarrow+2 \mathrm{H}_{2} \mathrm{O} \\
3 \mathrm{Mg}^{2+}+2 \mathrm{PO}_{4}^{3-} \rightarrow \mathrm{Mg}_{3}\left(\mathrm{PO}_{4}\right)_{2} \downarrow
\end{gathered}
$$

Reaction (1) is the anodic dissolution and (2) is the oxygen evolution reaction. The cation released from the metal (reaction (1)) combines with the anion in the electrolyte to form compounds $\mathrm{Mg}(\mathrm{OH})_{2}, \mathrm{Mg}_{2} \mathrm{AlO}_{4}, \mathrm{Mg}_{2} \mathrm{SiO}_{4}$ or $\mathrm{Mg}_{3}\left(\mathrm{PO}_{4}\right)_{2}$, depending on the different electrolyte by reactions (3), (5), (6) and (7). The unstable hydroxide $\mathrm{Mg}(\mathrm{OH})_{2}$ dehydrates to $\mathrm{MgO}$ by the high temperature (reaction (4)), resulting from the plasma discharge.

Relatively few published papers can be found that combine both tribological and corrosion studies of PEO treated Mg alloys. In this contribution, the authors' own work is primarily used to illustrate the general relationships between PEO processing parameters and the subsequent tribological-corrosion performance of the coatings.

\section{Corrosion and tribological properties of PEO-coated Mg-alloys}

\subsection{Corrosion resistance}

Magnesium alloys exhibit very poor corrosion resistance due to their chemically active nature, especially internal galvanic corrosion [12], which can further cause 
severe pitting corrosion on the metal surface resulting in decreased mechanical stability and an unattractive appearance. For coated metals, including Mg-alloys, the corrosion performance of coatings is determined by the time taken to initiate corrosion in the metal substrate since this is much shorter than the time taken for the coating to degrade [13]. Generally, the corrosion resistance of PEO-coated magnesium alloys depends on many factors that are summarized schematically in Fig 1. The overall protective abilities of the PEO coatings are governed by:

- Coating structures, mainly coating compactness in terms of porosity and other defect levels.

- Relative thicknesses of the three layers, particularly the coating/substrate interface layer.

- Chemical composition of the coating.

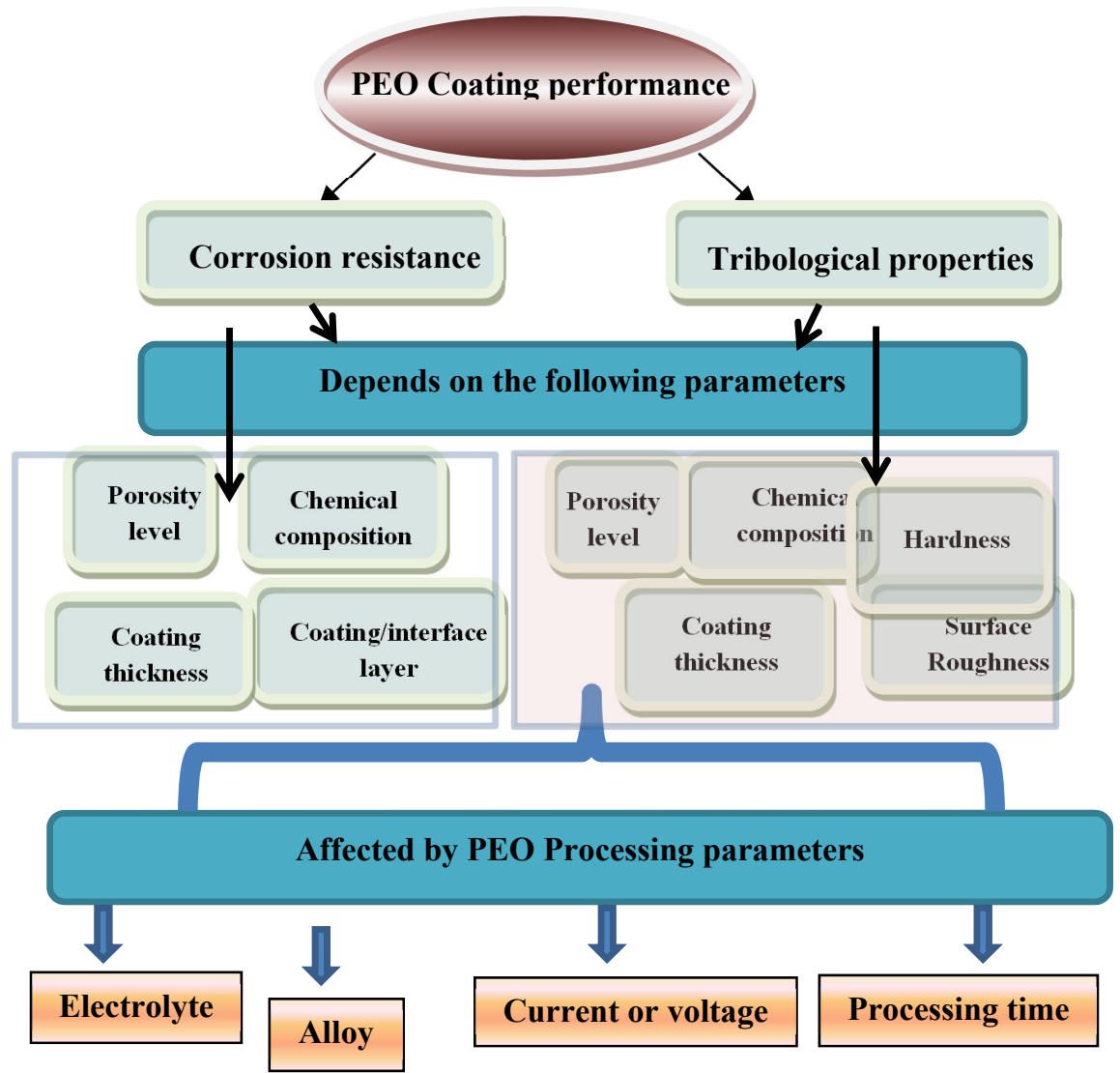

Figure 1: PEO processing parameters and performance. 
Therefore, the more compact and thicker the coating layers, the more difficult it is for the corrosive anions or oxidants $\left(\mathrm{Cl}^{-1}\right.$ ions) to penetrate to the base magnesium substrate. The coating/substrate barrier layer plays a key role in decreasing the substrate area exposed to the aggressive solution. The phases present in the oxide coatings are also important in the overall corrosion resistance. The spinel phases $\left(\mathrm{MgAl}_{2} \mathrm{O}_{4}, \mathrm{Mg}_{2} \mathrm{SiO}_{4}\right)$ are more resistant to dissolution than $\mathrm{MgO}$ which can quite readily be converted to $\mathrm{Mg}(\mathrm{OH})_{2}$ [14].

\subsection{Mechanical/tribological properties}

As a result of the PEO coating process, the magnesium alloy surface is converted into ceramic-like coating layers that are hard, well adhered to the substrate and wear resistant $[15,16]$. The mechanical and tribological properties of PEO coatings depend on the characteristics schematically shown in Fig. 1:

- Hardness is strongly dependent on the coating thickness, the nature of the dominant phases present, their ratio and distribution and the density of porosity and micro-cracks in the coatings $[9,17,18]$.

- The adhesion is influenced by the coating thickness. As the coating process progresses, significant changes take place in the inner layer structure as a result of diffusion processes [15] and adhesion is improved.

- The load that can be supported is affected by the coating thickness. Thicker coatings will give lower stresses at the coating-substrate interface and hence give better load support [9].

- The wear resistance of coatings mainly depends on hardness, coefficient of friction and roughness. Hence, porosity levels, chemical composition, thickness and structure of the coatings are key parameters for wear performance of $\mathrm{Mg}$ alloys [17]. As coating growth continues, the coating surface roughness and outer layer porosity level will increase with increasing processing time.

\subsection{Correlation between tribological and corrosion properties}

Since the coating hardness depends directly on the coating compactness, coatings produced with more porosity have lower hardness. Hence, a change of the process parameters, such as a current density and modes [5, 17] and electrolyte composition and concentration [4], are important in controlling porosity levels to improve coating hardness. Coatings produced in silicate solutions generally have a higher hardness than coatings produced in a phosphate solution under the same process conditions [18] since the oxide layers made in silicate solutions contain $\mathrm{Mg}_{2} \mathrm{SiO}_{4}$, which has a higher micro-hardness than $\mathrm{MgO}, \mathrm{MgAlPO}$ and $\mathrm{Mg}_{3}\left(\mathrm{PO}_{4}\right)_{2}$ that are produced in phosphate solutions [4]. The use of sodium aluminate $\left(\mathrm{NaAlO}_{2}\right)$ in the electrolyte for AJ62, AM60B and AZ91D Mg-alloys was investigated using different current modes $[5,8]$. PEO coatings can increase the hardness of the magnesium alloys 5-9 times compared with the hardness of the base substrate [17]. However, the values of micro-hardness close to the substrate/coating interface generally have the highest value compared to other locations, which may be attributed to its higher compactness compared with the 
outer porous layer [19]. The wear resistance of the coated samples is a complex process that involves surface roughness and hardness which are controlled by phase contents and porosity levels.

Since PEO coatings contain unavoidable pores, although most of them are discontinuous and the number of through thickness pores is very small, the overall corrosion resistance of PEO coated magnesium alloy depends on the retarding effect of the porosity level of the oxide layer and on the corrosion resistance of the substrate/coating interface [8]. However, the more compact and thicker the coating and presence of phases, the slower and more difficult access of the corrosive species can be. The electrochemical behaviour of magnesium alloys and PEO coatings have been mostly studied using potentiodynamic polarization in $3.5 \%$ $\mathrm{NaCl}$ solution at $25^{\circ} \mathrm{C}$ and electrochemical impedance spectroscopy (EIS). The presence of a PEO coated layer on the magnesium alloys causes a decrease of the corrosion current density by up to four orders of magnitude [8]. There are situations where the structures for good corrosion and wear performance are not the same. An example would be for oil-lubricated wear where the presence of a porous outer layer in the PEO coating could act as an oil reservoir, improving wear performance [20].

\section{Illustrative examples}

In this section, it is shown how a coating can be formed with both good corrosion and wear properties by varying the PEO process parameters, in particular the electrolyte chemistry (concentration, composition) and current mode.

\subsection{Experimental procedures}

Commonly used Mg-alloys AZ91D (mass fraction: Al 9\%, Mn 0.15\%, Zn 0.8\%, Si $0.1 \%$, balance Mg), AM60B (mass fraction: Al 5.6-6.4\%, Mn 0.26-0.4\%, $\mathrm{Zn} \leq 0.2 \%$, balance Mg) and AJ62 (mass fraction: Al 6.1\%, Mn 0.34\%, Sr 2.1\%, balance $\mathrm{Mg}$ ) are used as example materials. The PEO coating system used to produce the oxide coatings consists basically of a container with alkaline electrolyte and an electrical source and is described in more detail in refs. [5] and [15]. A stainless steel plate in the bath acts as a counter-electrode (cathode) with the Mg-alloy coupons as the anode. The electrodes are connected to two pulsed DC power supplies operating under a constant current control function to generate different current waveforms.

\subsection{Effect of electrolyte chemistry}

\subsubsection{Electrolyte concentration}

PEO coatings were produced on AZ91D Mg-alloy using a base composition of $2 \mathrm{~g} / \mathrm{K} \mathrm{KOH}$ electrolyte and addition of two different aluminate $\mathrm{Na}_{2} \mathrm{Al}_{2} \mathrm{O}_{4}$ concentrations $8 \mathrm{~g} / \mathrm{l}$ (S1) and $15 \mathrm{~g} / \mathrm{l}$ (S2). The PEO-coated materials show a higher coefficient of friction (COF), Fig. 2(a), but a lower wear rate, Fig. 2(b), than the uncoated alloy. 


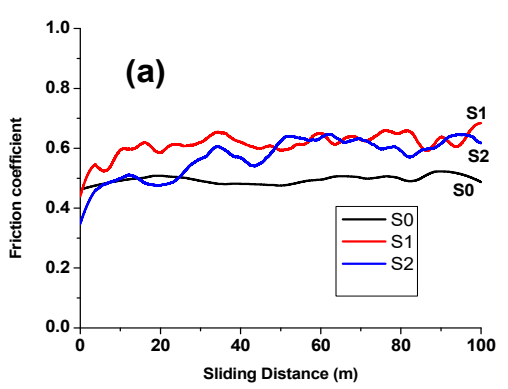

(b) Wear rate $\times 10^{-3}$
$\mathrm{~mm}^{3} / \mathrm{Nm}$
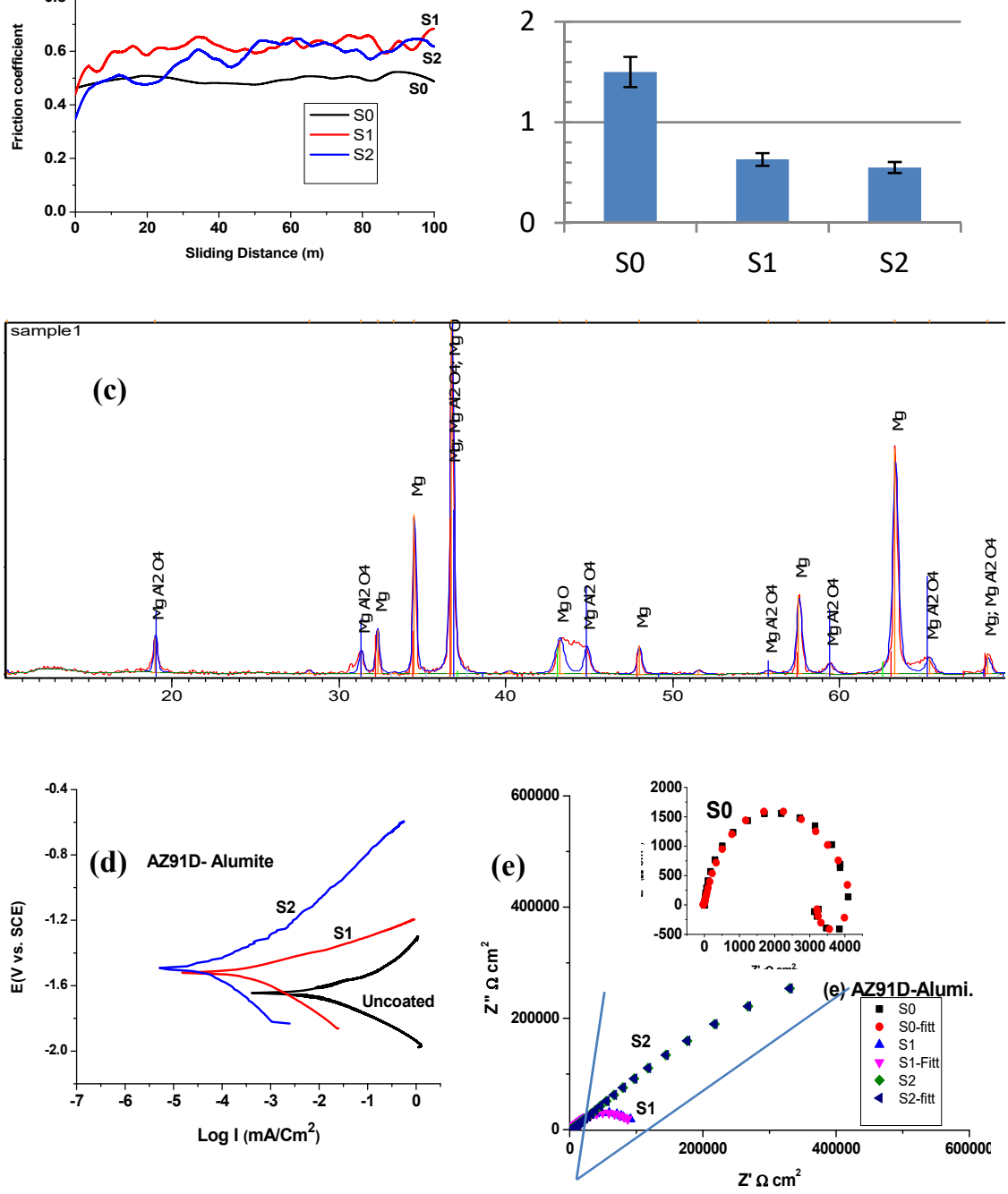

Figure 2: (a) Coefficients of friction vs. sliding distance for samples S1 and S2 and S0 uncoated Mg alloy substrate; (b) wear rates of the oxide coatings on AZ91D alloy for different electrolyte concentrations; (c) XRD pattern for S2 and (d) potentiodynamic corrosion resistance; and (e) EIS results. 
As shown in Fig. 2(c), from the XRD pattern of the oxide coating made using a concentrated aluminate electrolyte, the coatings were mainly composed of $\mathrm{MgAl} 2 \mathrm{O} 4$ and $\mathrm{MgO}$ phases. Based on the potentiodynamic polarization and EIS results (shown in Figs. 2(d) and (e)), it was found that all PEO coatings offered significant corrosion protection to the AD91D alloy for short immersion times $(0.33 \mathrm{~h})$ prior to corrosion testing.

Compared to uncoated alloy, the corrosion rate from potentiodynamic polarization was reduced by at least 50 and 300 times for S1 and S2, respectively. The EIS results demonstrated the same trends. As can be seen from Fig. 2(e), the impedance response of the uncoated $\mathrm{Mg}$ alloys (the enlarged graph) is very different from that of the coated specimens. The differences in impedance are related to the corrosion protection mechanisms for the alloys provided by the naturally formed oxide layer (few $\mathrm{nm}$ ) which is easily corroded by the corrosive electrolyte. Sample S2, produced with a concentrated aluminate electrolyte, shows that both the tribological and corrosion properties can be enhanced at the same time. Increasing the aluminate concentration in the electrolyte from 8 to $15 \mathrm{~g} / \mathrm{l}$ produces a coating that is denser and contains a higher amount of the spinel phase $\mathrm{MgAl}_{2} \mathrm{O}_{4}$ relative to $\mathrm{MgO}$. This produces a more corrosion and wear resistant coating. The thickness, porosity and defect levels are decreased by using a concentrated aluminate-containing electrolyte.

\subsubsection{Electrolyte composition}

The electrolyte composition plays a key role in the PEO process and polyvalent metal anions, such as tungstate, are promising for the formation of coatings of different chemical compositions that enhance both corrosion and tribological performances. PEO coatings were produced on AZ91D Mg-alloy using a bipolar current mode and an electrolyte with a base composition of $8 \mathrm{~g} / 1 \mathrm{Na}_{2} \mathrm{Al}_{2} \mathrm{O}_{4}+1 \mathrm{~g} / \mathrm{l}$ $\mathrm{KOH}$ and additions of $0,1,2$ and $6 \mathrm{~g} / \mathrm{l}$ of $\mathrm{Na}_{2} \mathrm{WO}_{4}$ [21]. The Nyquist and the Bode (frequency dependencies of impedance modulus $|Z|$ ) diagrams from the EIS analysis of experimental and fitted curves of uncoated and PEO-coated materials for $0.33 \mathrm{~h}$ immersion time are given in Fig. 3. Table 1 summarizes all the fitted EIS results for the uncoated and PEO coated samples. The choice of equivalent
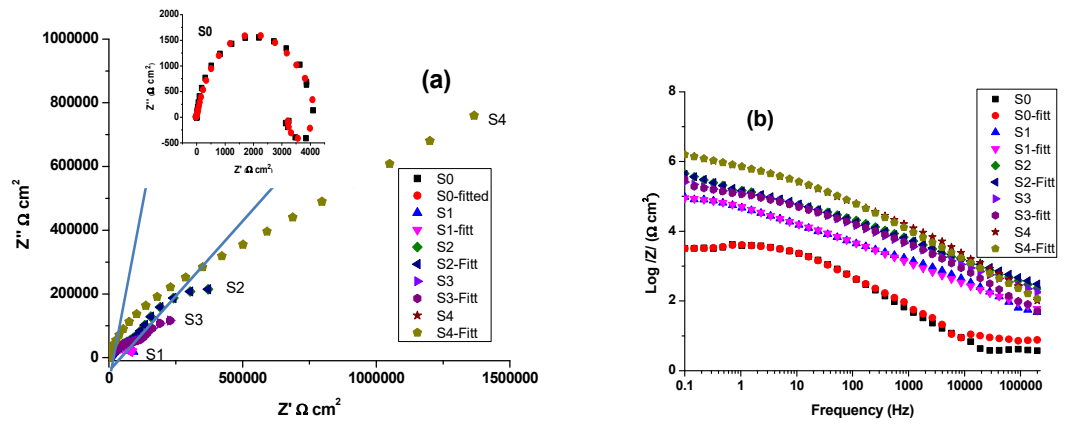

Figure 3: Plots of uncoated and PEO coated AZ91D Mg alloy after $0.33 \mathrm{~h}$ immersion time (a) Nyquist and (b) Bode plot-impedance. 
Table 1: Tungstate composition, thickness and fitting results of EIS diagrams in $3.5 \%$ wt $\mathrm{NaCl}$ solution, for $0.33 \mathrm{~h}$ immersion time of the uncoated (S0) (equiv. circuit Rs+CPE1/(R1+CPE2/R2+L)) and of PEO treated AZ91D Mg alloy using four different tungstate concentration (equiv. circuit Rs+ CPE1/(R1+ CPE2/R2)).

\begin{tabular}{|c|c|c|c|c|c|c|c|c|c|}
\hline $\mathrm{S}$ & $\begin{array}{c}\mathrm{Na}_{2} \mathrm{WO}_{4} \\
\mathrm{~g} / 1\end{array}$ & \begin{tabular}{|c|} 
Coating \\
thickness \\
$\mu \mathrm{m}$
\end{tabular} & $\begin{array}{l}\text { CPE1- } Q \\
\mu \mathrm{F} / \mathrm{cm}^{2} \mathrm{~s}^{1-\mathrm{n}}\end{array}$ & CPE1- $n$ & $\begin{array}{c}\mathrm{R} 1 \\
\mathrm{k} \Omega \cdot \mathrm{cm}^{2}\end{array}$ & $\begin{array}{c}\text { CPE2- } Q \\
\mu \mathrm{F} / \mathrm{cm}^{2} \mathrm{~s}^{1-\mathrm{n}}\end{array}$ & CPE2- $n$ & $\begin{array}{c}\mathrm{R} 2 \\
\mathrm{k} \Omega \cdot \mathrm{cm}^{2}\end{array}$ & $\begin{array}{c}\mathrm{L} \\
\mathrm{H}^{*}\end{array}$ \\
\hline S0 & ---- & 0 & 18.66 & 0.73 & -15.65 & -2.498 & 0.33 & 18 & 0.25 \\
\hline S1 & 0.0 & $25.2 \pm 2.5$ & 3.499 & 0.621 & 0.049 & 1.235 & 1 & 270 & \\
\hline S2 & 1.0 & $30.0 \pm 3.0$ & 1.247 & 0.563 & 0.244 & 1.528 & 1 & 899 & \\
\hline S3 & 2.0 & $28.5 \pm 2.9$ & 1.38 & 0.584 & 0.324 & 0.001 & 0 & 710 & \\
\hline S4 & 6.0 & $43.4 \pm 4.5$ & 0.187 & 0.675 & 0.978 & 0.907 & 0.713 & 2269 & \\
\hline
\end{tabular}

*Only applicable to uncoated material.

circuits employed for curve fitting was a balance between a reasonable fitting of the experimental values and a good description of the electrochemical system by keeping the number of circuit elements at a minimum [5].

The proposed equivalent circuit used describes the behaviour of a process characterized by two time constants, namely a high-frequency (HF) time constant (CPE1-R1) and a low-frequency (LF) time constant (CPE2-R2). The low frequency data are on the right side of the Nyquist plot and higher frequency data are on the left. CPE2 is the constant phase element for the double layer capacitance of the interface at, or near, the coating/substrate interface. R2 represents the polarization resistance which is the Faradic charge transfer resistance related to electrochemical reactions in the same coating/substrate interface region [5]. It is R2 that primarily controls the corrosion resistance of the coated alloy. The impedance of the CPE is given by the equation:

$$
Z_{C P E}=1 /\left[Q(j \omega)^{n}\right]
$$

where $Z_{C P E}\left(\Omega \cdot \mathrm{cm}^{2}\right)$ is the impedance of the constant-phase-element; $Q$, a CPE constant $\left(\Omega^{-1} \mathrm{~s}^{n} \mathrm{~cm}^{-2}\right)$, is a combination of properties related to both the surface and the electroactive species and is independent of frequency, $j$ is the imaginary unit $\sqrt{-1}, \omega=2 \pi f$ the angular frequency ( $\mathrm{rad} / \mathrm{s})$ of the sine wave, $f$ the frequency in $\mathrm{Hz}$; the value of $n$ ranges between 0 and 1. Depending on the value of exponent $n$, the physical meaning of the CPE of the circuit can be related to pure resistance $(n=0)$, pure capacitance $(n=1)$, pure inductance $(n=-1)$, or mass transport related impedance, i.e. Warburg impedance $(n=0.25-0.5)$. For the uncoated samples, the presence of Warburg element and its resistance R3 is evidence for a diffusion control process.

The tungstate addition produces changes in the microstructure and phase contents of the coatings. Increasing the tungstate content from 0 to $6 \mathrm{~g} / \mathrm{l}$ in the electrolyte increases the thickness of the dense substrate/coating interface layer, 
enhances the corrosion resistance for immersion times $(0.33 \mathrm{~h})$ prior to corrosion, reduces the surface roughness which leads to a decrease in the COF in dry sliding wear (Fig. 4), and leads to the formation of the tungstate-containing phases $\mathrm{WO}_{3}$ and $\mathrm{MgWO}_{4}$ (see Fig. 5). All these factors, together with a reduction in porosity, leads to a harder coating with lower wear rates.

Fig 4(b) shows that sample S4 treated with high tungstate concentrations exhibits a lower coefficient of friction (COF) compared with that of samples treated without tungstate or with lower tungstate concentrations. However, the uncoated samples exhibit the minimum COF. The lowest wear rate was produced with the highest tungstate addition. However, all PEO coated samples show a lower wear rate than the uncoated alloy, Fig. 4(a). In the pin-on-disk tests, the COF is shown to be directly dependent on the surface roughness's parameters as shown in Fig. 6(b). The tungstate ions may also serve as a corrosion inhibitor and promote the formation of a passive film, which is essential for the deposition of PEO coatings on the $\mathrm{Mg}$ alloys.
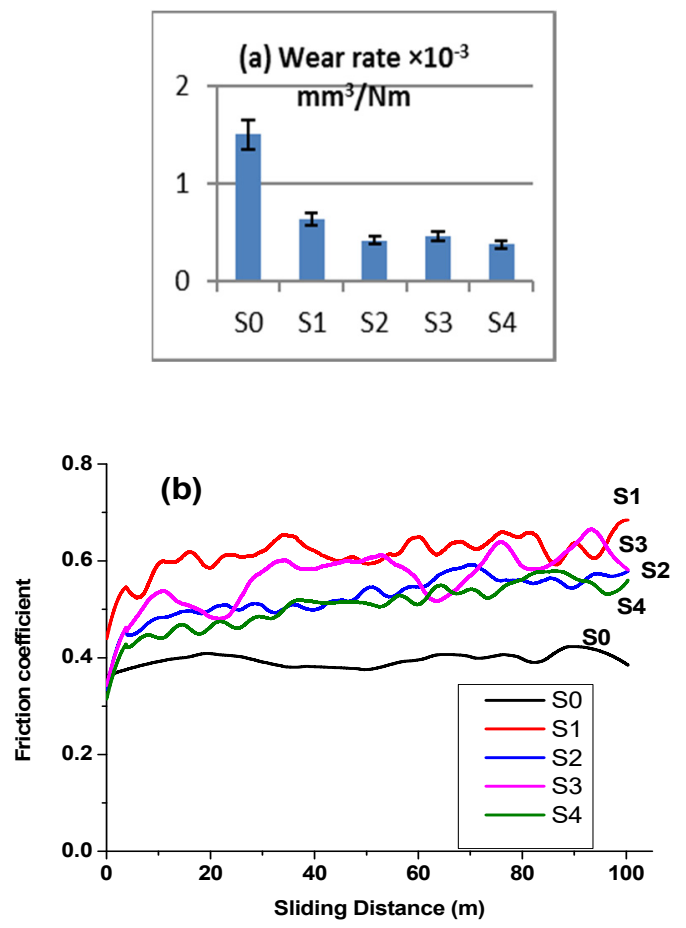

Figure 4: (a) Wear rates and (b) coefficient of friction vs. sliding distance of the uncoated $\mathrm{Mg}$ alloy substrate and the oxide coatings formed using different tungstate concentrations. 


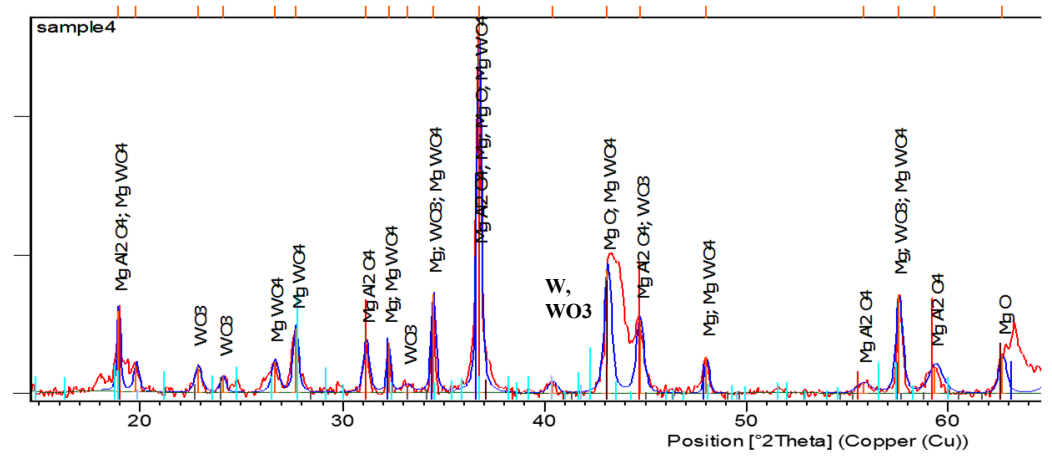

Figure 5: XRD patterns of oxide coatings formed in $\mathrm{Na}_{2} \mathrm{Al}_{2} \mathrm{O}_{4}+1 \mathrm{~g} / \mathrm{K} \mathrm{KOH}$ electrolyte with addition of $6.0 \mathrm{~g} / 1 \mathrm{Na}_{2} \mathrm{WO}_{4}$ (sample $\mathrm{S} 4$ ).
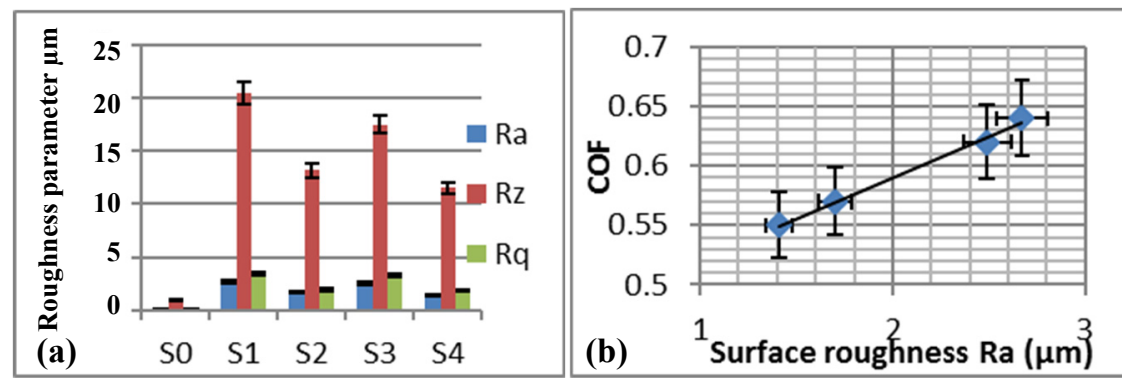

Figure 6: (a) Roughness parameters $R_{a}, R_{z}$ and $R_{q}$ of the oxide coatings formed using different tungstate concentrations and the S0 uncoated $\mathrm{Mg}$ alloy substrate. (b) Coefficients of friction vs. roughness parameter $R_{a}$ of the oxide coatings on AZ91D-Mg alloy substrate.

\subsection{Effect of current mode}

The influence of current mode (unipolar U, bipolar B or hybrid H1 (unipolar followed by bipolar) and $\mathrm{H} 2$ (bipolar followed by unipolar)) on the corrosion and wear properties of PEO coatings formed on an AM60B magnesium alloy was investigated and are shown in Figs. 7 and 8 [5]. The wear resistance was evaluated using a pin-on-disk set-up under dry conditions and an applied load of 2 N. PEO coating decreases the wear rate, Fig. 7(a), but also increases the COF (Fig. 7(b)). This increase in COF is related to an increase in surface roughness, Fig. 7(c). Corrosion testing was performed in a $3.5 \mathrm{wt} \% \mathrm{NaCl}$ solution using a potentiodynamic polarization technique. $R_{p}$, the polarization resistance, was used as the measure of corrosion resistance. The results are summarized in Fig. 8 and Table 2.

The reduction of the porosity and other defects, e.g. micro cracks, gas trapping, discontinuity between the coatings and the substrate, of the coatings, together with 
lower surface roughness that are produced by the B and $\mathrm{H} 1$ current modes compared to the $\mathrm{U}$ and $\mathrm{H} 2$ modes lead to improvement in both corrosion and wear resistance (including a decrease in COF), even though the coatings were thinner. Use of a bipolar current mode reduces the number of large pancake features on the surface, thus lowering the surface roughness and COF. In the pin-on-disk tests, the COF is shown to be directly dependent on the surface roughness, $R_{z}$ (Fig. 7(d)). The corrosion performance is more closely related to the protective nature of the dense oxide layer at the coating/substrate interface. In this regard, the most protective oxide is formed by using the bipolar and hybrid 1 (H1) current modes (Fig. 8).
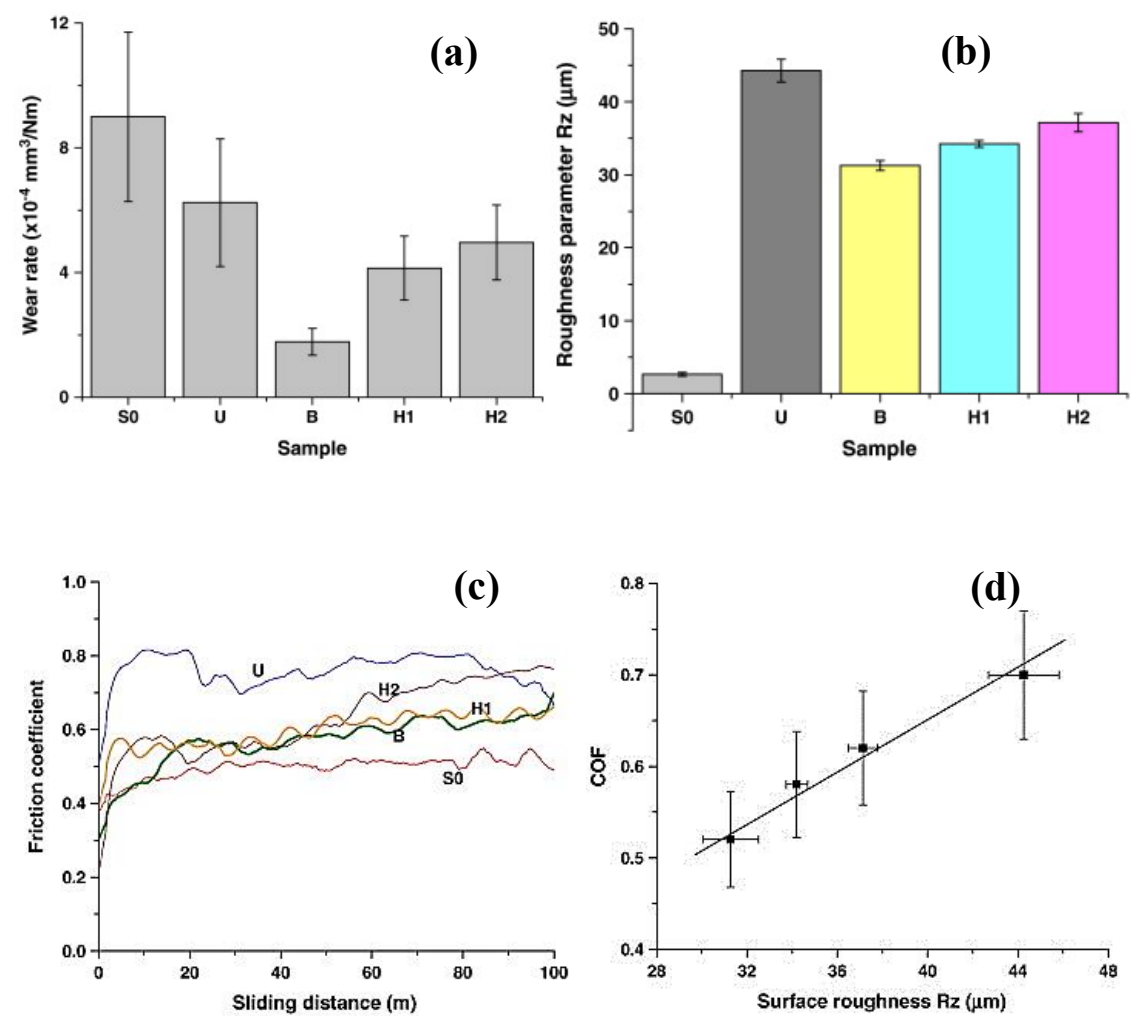

Figure 7: Wear rate (a), roughness parameter $\mathrm{Rz}$ (b), coefficients of friction vs. sliding distance (c) and coefficients of friction vs. roughness parameter $\mathrm{Rz}$ (d) for samples $\mathrm{U}, \mathrm{B}, \mathrm{H} 1$, and $\mathrm{H} 2$ and the $\mathrm{S} 0$ uncoated AM60B Mg alloy substrate and $\mathrm{H} 2$ and the $\mathrm{S} 0$ uncoated $\mathrm{AM} 60 \mathrm{~B} \mathrm{Mg}$ alloy substrate. 


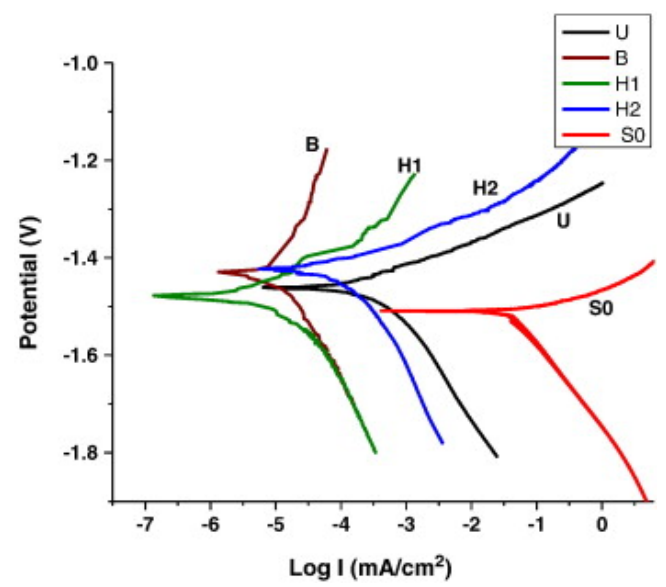

Figure 8: Potentiodynamic polarization curves of the uncoated (S0) and coated AM60B alloy samples using unipolar (U1), bipolar (B) and hybrid (H1 and H2) current modes.

Table 2: Characterization of coated samples and dry sliding wear results.

\begin{tabular}{|c|c|c|c|c|c|c|}
\hline S & $\begin{array}{c}\text { Coating } \\
\text { thickness } \\
(\mu \mathrm{m})\end{array}$ & $\begin{array}{c}\text { Surface } \\
\text { roughness } R_{z} \\
(\mu \mathrm{m})\end{array}$ & $\begin{array}{c}\text { Level of } \\
\text { porosity and } \\
\text { other defects }\end{array}$ & $\begin{array}{c}R_{p} \\
\Omega \cdot \mathrm{cm}^{2}\end{array}$ & COF & $\begin{array}{c}\text { Wear rate } \\
\times 10^{-4} \mathrm{~mm}^{3} / \mathrm{N} \mathrm{m}\end{array}$ \\
\hline $\mathrm{U}$ & 40 to 55 & $44.3 \pm 1.6$ & $\begin{array}{c}\text { Porous with } \\
\text { many } \\
\text { microcracks }\end{array}$ & $5.8 \mathrm{E} 07$ & $\begin{array}{c}0.72 \text { to } \\
0.8\end{array}$ & $6.24 \pm 2.0$ \\
\hline B & 31 to 42 & $31.3 \pm 0.7$ & $\begin{array}{c}\text { Low level of } \\
\text { porosity and } \\
\text { microcracks }\end{array}$ & $8.4 \mathrm{E} 08$ & $\begin{array}{c}0.55 \text { to } \\
0.6\end{array}$ & $1.78 \pm 0.4$ \\
\hline H1 & 22 to 38 & $34.2 \pm 0.5$ & $\begin{array}{c}\text { Low level of } \\
\text { porosity and } \\
\text { microcracks }\end{array}$ & $4.5 \mathrm{E} 09$ & 0.55 to \\
0.6 & $4.14 \pm 1.0$ \\
\hline H2 & 21 to 39 & $37.1 \pm 1.2$ & $\begin{array}{c}\text { Intermediate } \\
\text { level of } \\
\text { microcracks } \\
\text { and porosity }\end{array}$ & $1.9 \mathrm{E} 08$ & 0.65 to \\
0.7 & $4.96 \pm 1.2$ \\
\hline S0 & NA & $2.6 \pm 0.2$ & NA & $2.8 \mathrm{E} 05$ & 0.4 to \\
0.5
\end{tabular}

\section{Conclusions}

The PEO process for coating Mg alloys is strongly influenced by such parameters as electrolyte composition and concentration as well as current mode (unipolar, bipolar and hybrid i.e. combination of both). Generally, these parameters have a direct influence on the discharging behaviour, porosity and microcrack levels, 
roughness, phase transformations, crystallization and sintering. This, then, affects the physical, mechanical and chemical properties of the coating. For PEO-coated materials, the primary enhancement of the corrosion and wear resistance comes from:

- the inner dense barrier layer, but also from the relatively dense intermediate layer.

-The denser coatings with lower surface roughness that are produced by the bipolar and hybrid (unipolar followed by bipolar) current modes lead to improved corrosion resistance and tribological performance compared to those produced using a unipolar or hybrid (bipolar followed by unipolar) current modes.

- Each coating has a different phase composition and surface morphology due to the effect of different electrolyte chemistry. It has been shown that increases in the $\mathrm{MgAl}_{2} \mathrm{O}_{4}$ spinel phase content and the tungstate-containing phases including $\mathrm{WO}_{3}$ and $\mathrm{MgWO}_{4}$, together with a reduction in porosity, lead to coatings with lower wear rates as well as increased corrosion resistance.

\section{References}

[1] Mordike, B.L. \& Ebert, T., Magnesium properties-applications-potential. Materials Science and Engineering, A302, pp. 37-45, 2001.

[2] Hussein, R.O. \& Northwood, D.O. Improving the performance of magnesium alloys for automotive applications. WIT Transactions on the Built Environment, 137, pp. 531-544, 2014.

[3] Dobrzanski, L.A., Tanski, T., Cizek, L. \& Domagala, J., Mechanical properties and wear resistance of magnesium casting alloys. Journal of Achievements in Materials and Manufacturing Engineering, 31(1), pp. 83-90, 2008.

[4] Hussein, R.O. \& Northwood, D.O., Production of anti-corrosion coatings on light alloys (Al, Mg, Ti) by plasma electrolytic oxidation (PEO). Developments in Corrosion Protection, ed. M. Aliofkhazraei, InTech Open Publishers, 2013.

[5] Hussein, R.O., Zhang, P., Nie, X., Xia, Y. \& Northwood, D.O., The effect of current mode and discharge type on the corrosion resistance of plasma electrolytic oxidation (PEO) coated magnesium alloy AJ62. Surface \& Coatings Technology, 206, pp. 1990-1997, 2011.

[6] Apelfeld, A.V., Borisov, A.M., Krit, B.L., Ludin, V.B., Polyansky, M.N., Romanovsky, E.A., Savushkina, S.V., Suminov, I.V., Tkachenko, N.V., Vinogradov, A.V. \& Vostrikov, V.G., The study of plasma electrolytic oxidation coatings on $\mathrm{Zr}$ and $\mathrm{Zr}-1 \% \mathrm{Nb}$ alloy at thermal cycling. Surface \& Coatings Technology, 269, pp. 279-285, 2015.

[7] Chen, Y., Nie, X., Northwood, D.O., Investigation of plasma electrolytic oxidation (PEO) coatings on a $\mathrm{Zr}-2.5 \mathrm{Nb}$ alloy using high temperature/pressure autoclave and tribological tests. Surface \& Coatings Technology, 205, pp. 1774-1782, 2010. 
[8] Hussein, R.O., Nie, X. \& Northwood, D.O., The application of plasma electrolytic oxidation (PEO) to the production of corrosion resistant coatings on magnesium alloys: a review. Corrosion \& Materials, 38(1), pp. 54-65, 2013.

[9] Yerokhin, A.L., Nie, X., Leyland, A., Matthews, A. \& Dowey, S.J., Plasma electrolysis for surface engineering, Surface \& Coatings Technology, 122, pp. 73-93, 1999.

[10] Hussein, R.O., Nie, X. \& Northwood, D.O., Processing-structure-propertiesperformance relationships for Mg-Alloys coated using plasma electrolytic oxidation (PEO) method. Materials Forum, 37, In press, 2014.

[11] Duan, H., Yan, C. \& Wang, F., Effect of electrolyte additives on performance of plasma electrolytic oxidation films formed on magnesium alloy AZ91D. Electrochimica Acta, 52, pp. 3785-3793, 2007.

[12] Roberge, P.R., Corrosion Engineering Principles and Practice, McGraw Hill: New York, 2008.

[13] George, G.A., Colwell, J.M., Trueman, T. \& Will, G., Sensitive methods for studying the environmental performance of protective coatings. Corrosion \& Materials, 39(2), pp. 46-53, 2014.

[14] Liu, L., Yang, P., S C., Guo H., An M., Microstructure and corrosion behavior of micro-arc oxidation film on magnesium alloy. International Journal of Electrochemical Science, 8, pp. 6077-6084, 2013.

[15] Hussein, R.O., Nie, X. \& Northwood, D.O., An investigation of ceramic coating growth mechanisms in plasma electrolytic oxidation (PEO) processing. Electrochimica Acta, 112, pp. 111-119, 2013.

[16] Khan, R., Yerokhin, A.L., Pilkington, T., Leyland, A. \& Matthews A., Residual stresses in plasma electrolytic oxidation coatings on Al alloy produced by pulsed unipolar current. Surface \& Coatings Technology, 200, pp. 1580-1586, 2005.

[17] Durdu, S., Bayramoglu, S., Demirtas, A., Usta, M. \& Ücısık, A.H., Characterization of AZ31 Mg alloy coated by plasma electrolytic oxidation. Vacuum, 88, pp. 130-133, 2013.

[18] Liang, J., Hu, L. \& Hao, J., Characterization of microarc oxidation coatings formed on AM60B magnesium alloy in silicate and phosphate electrolytes, Applied Surface Science, 253(10), pp. 4490-4496, 2007.

[19] Li, Z., Yuan, Y. \& Jing, X., Effect of current density on the structure, composition and corrosion resistance of plasma electrolytic oxidation coatings on Mg-Li alloy. Journal of Alloys and Compounds, 541, pp. 380391, 2012.

[20] Guo, L.J.W., Liang, J., Xue, Q. \& Yan F., Tribological behavior of plasma electrolytic oxidation coating on magnesium alloy with oil lubrication at elevated temperatures. Journal of Alloys and Compounds, 481, pp 903-909, 2009.

[21] Hussein, R.O., Nie, X. \& Northwood, D.O., Plasma electrolytic oxidation (PEO) coatings on magnesium alloy AZ91D for improved corrosion and wear resistance. CAMS2014 Conference, Combined Australian Materials Societies, Sydney, Australia, paper V1.3, November 2014. 